\title{
Irrigação, matéria orgânica e cobertura morta na produção de mudas de cumaru (Amburana cearensis)
}

\author{
João V. F. Pimentel ${ }^{1} \&$ Hugo 0. C. G uerra ${ }^{2}$
}

\section{RESU M O}

Conduziu-se um experimento em um viveiro visando estudar os efeitos da irrigação, da adubação orgânica e da cobertura morta no solo, sobre o crescimento das mudas de cumaru (Amburana cearensis), planta nativa de múltiplas utilidades. Cinco quantidades de água foram aplicadas no solo, determinadas em função da evapotranspiração $(0,25 ; 0,50 ; 0,75 ; 1,00 ; 1,25 \mathrm{ET})$; três níveis de esterco de boi no solo, como fração do volume total do solo $(0,25 ; 0,50 ; 0,75)$ e presença e ausência de cobertura morta. 0 delineamento experimental foi em blocos casualizados, com quatro repetições. Aos 147 dias após a semeadura, observou-se que, com exceção da altura das plantas, afetada pela cobertura do solo, nenhuma das variáveis estudadas foi afetada significativamente pelos tratamentos utilizados. 0 cumaru parece adaptar-se às condições adversas de água e matéria orgânica no solo. A presença de cobertura morta no solo além de aumentar a altura das mudas significou uma economia de $41 \%$ da água de irrigação utilizada.

Palavras-chave: caatinga, água do solo, planta nativa, esterco

\section{Irrigation, organic matter and mulching in production of the seedlings of 'cumaru' (Amburana cearensis)}

\begin{abstract}
A B STRACT
An experiment with 'cumaru' (Amburana cearensis), semi-arid native tree of multiple uses, was conducted under semi controlled conditions aiming to study the effects of irrigation, organic matter fertilization and mulching on the seedling growth. Five water regimes, based on the water evapotranspiration, $(0.25$; $0.50 ; 0.75 ; 1.00$ and $1.25 \mathrm{ET})$; three levels of manure application, as fraction of the total volume of the soil $(0.25 ; 0.50$ and 0.75$)$ with and without mulching were studied. The experimental design was a factorial in randomized blocks and four replicates. O ne hundred and forty seven days after sowing, it was observed that with the exception of the plant height none of the studied variables were affected by the treatments. It seems that the 'cumaru' is a highly adapted plant to soil water stress and organic matter. The presence of mulching besides increasing the seedling height presented a $41 \%$ irrigation water economy.
\end{abstract}

Key words: scrubland, soil water, native plant, manure 


\section{INTRODUÇÃO}

O cumaru, Amburana cearensis (Allem.) A.C. Smith, é uma planta de múltiplas utilidades; sua madeira, de excelente qualidade, fácil de ser trabalhada e com aroma agradável, é vendida no comércio com o nome de cerejeira; suas raízes, entrecasca e sementes, produzem a cumarina, princípio ativo utilizado na indústria alimentícia (doces e biscoitos), de cigarro e tabaco, indústrias de perfume como fixador, além de ser usado na produção de medicamentos, como o xarope de cumaru ou lambedor caseiro, de largo uso popular e de eficácia comprovada cientificamente, como antiinflamatório e bronco-dilatador (Canuto et al., 2010). É uma árvore que, por sua beleza, pode ser usada como ornamental em projetos paisagísticos. Para recuperação de solos e restauração florestal de áreas degradadas é utilizada tanto na fase inicial como nas fases posteriores do reflorestamento, inclusive como mata ciliar, em locais com inundações periódicas de curta duração. Em sistemas agroflorestais pode ser usada como quebra-ventos e faixas arbóreas entre plantações. Como forrageira, suas folhas e vagens são consumidas pelos caprinos, tanto verdes como secas e pelos bovinos, depois de secas. É também de grande importância para a apicultura e meliponicultura pelo fato de fornecer néctar na estação seca do ano, figurando entre as 18 espécies mais utilizadas pelas abelhas nativas para coleta de pólen e/ou néctar e como local de nidificação, além da utilização da sua madeira na construção de colméias (Marinho et al., 2002).

Trovão et al. (2007) indicam que $A$. cearensis é uma espécie pouco sensível à variação do conteúdo de água do solo e que, para isto, o cumaru e outras espécies nativas da Caatinga, desencadeiam muitas medidas funcionais para sobreviver em condições de estresse hídrico; entre as quais, modificações anatomomorfológicas, que incluem aprofundamento do sistema radicular, diminuição no tamanho da folha, expansão caulinar e perda de folhas, dentre outras. Estas medidas provavelmente significam gasto de energia e diminuição do crescimento.

A matéria orgânica, procedente de animais como é o caso do conhecido esterco bovino e outros de origem vegetal obtidos de restos de culturas, posteriormente decompostos pelo processo da atividade microbiana, são ricos componentes capazes de aumentar a produtividade agrícola das culturas.

Muitas técnicas e alternativas de manejo do solo já foram e estão sendo empregadas e comparadas, a fim de se minimizar os impactos das altas temperaturas dos solos tropicais, entre estas o uso de coberturas protetoras, visto que podem modificar as variações de temperatura no interior do solo, particularmente próximo da superfície, podendo alterar consideravelmente o ambiente para o desenvolvimento da flora e da fauna do solo (Borkert et al., 2003; Resende et al., 2005; Gasparim et al., 2005). A exposição do solo descoberto, arado e gradeado intensivamente e exposto ao impacto direto das gotas de chuva provoca um fracionamento dos agregados formando crostas superficiais, e é responsável por uma acentuada degradação resultante da erosão hídrica, que em algumas regiões se constitui em um dos maiores problemas da agricultura. $\mathrm{O}$ uso de cobertura vegetal morta por ser simples e eficaz, torna-se uma maneira das mais econômicas para reduzir os danos causados pela ação erosiva das gotas de chuva. Esta eficácia deve-se à proteção que restos de culturas oferecem contra o impacto direto das gotas de chuva na superfície do solo reduzindo a velocidade de escoamento superficial, por aumento da rugosidade e favorecimento no processo de infiltração da água no perfil. Além disto, a cobertura morta diminui também o consumo de água, pela diminuição na evapotranspiração (Carvalho et al., 2003).

A produção de mudas de qualidade é um dos fatores a ser considerado, visto que, a escolha de um bom substrato faz com que as mudas, principalmente na etapa inicial, tenham capacidade de resistir às variadas condições adversas presentes nos locais em que é feito o plantio, razão por que alternativas de substratos devem ser testadas para a revegetação de áreas (Duarte et al., 2010). Resende et al. (2010) afirmam que cada espécie vegetal tende a apresentar preferências por uma determinada combinação de substratos.

Em experimento com cumaru (Amburana cearensis), Angelim et al. (2007), trabalharam com quatro tratamentos de matéria orgânica no solo: $\mathrm{T} 1=$ solo puro $(100 \%), \mathrm{T} 2=75 \%$ solo $+25 \%$ esterco umificado, $\mathrm{T} 3=50 \%$ solo $+50 \%$ esterco umificado e $\mathrm{T} 4$ $=25 \%$ solo $+75 \%$ esterco umificado. Os referidos autores concluíram que a espécie parece estar bem adaptada às condições adversas, como falta de água e também à reduzida concentração de matéria orgânica, de macro e de micronutrientes no solo. Esta adaptação deve, provavelmente, ter contribuído para que as plantas apresentassem o melhor crescimento e desenvolvimento morfológico em solo sem aplicação de matéria orgânica (Angelim et al., 2007). Guedes et al. (2010), trabalhando com substratos e temperaturas para testes de germinação e vigor de sementes de Amburana cearensis (Allemão) A.C. Smith, concluíram que a temperatura de $35^{\circ} \mathrm{C}$ mostrou-se mais adequada para a condução dos testes de germinação e vigor, independentemente do substrato utilizado. Os substratos areia e vermiculita foram os mais apropriados para avaliação da qualidade fisiológica das sementes.

Pelo modo como o cumaru é explorado, em extrativismo vegetal, com a prática do "anelamento" da casca, comprometese a sobrevivência da espécie no bioma Caatinga, ficando a mesma em risco de extinção. Daí a necessidade de maiores estudos sobre a produção de mudas do cumaru, para multiplicação da espécie, levando-se em consideração a realidade local, específica do semiárido. Considerando-se a escassez de informações com respeito a esta cultura visa-se, na presente pesquisa, avaliar o crescimento e o comportamento do cumaru na fase de mudas irrigadas em ambiente protegido, com variação nas quantidades de água, matéria orgânica no solo e cobertura morta além de se desenvolver uma tecnologia para a produção de mudas em vasos.

\section{Material e MÉTODOS}

O experimento foi desenvolvido em condições de ambiente protegido, no viveiro de mudas pertencente ao Núcleo de Educação Ambiental (NEA), antigo Horto Florestal, vinculado ao Instituto Brasileiro de Meio Ambiente (IBAMA), em 
Quixeramobim, CE, com as seguintes coordenadas geográficas: $5^{\circ} 12^{\prime} 08^{\prime \prime}$ de latitude sul, 39 $17^{\circ} 11^{\prime \prime}$ de longitude oeste e uma altitude de $196 \mathrm{~m}$. O clima do município de Quixeramobim é tropical seco semiárido, enquadrando-se na classificação climática de Köppen como BShw'. Clima chuvoso, com quatro meses de duração, de fevereiro a maio; Seco, com oito meses de duração, sem chuvas, de junho a janeiro, sendo os meses de outubro a dezembro os mais secos, e consequentemente os mais quentes. A precipitação pluviométrica é bastante variada, com uma média anual de 707,7 $\mathrm{mm}$. A temperatura em graus centígrados: máxima registrada $38^{\circ}$, média máxima $32^{\circ}$, mínima registrada $16,8^{\circ}$, média mínima $24^{\circ}$. A velocidade dos ventos é, em media, de $1,44 \mathrm{~km} \mathrm{~h}^{-1}$, geralmente soprando do litoral do estado para o sertão.

Testaram-se três níveis de matéria orgânica no solo: $\mathrm{N}_{1}$ (com $25 \%$ de esterco no solo), $\mathrm{N}_{2}$ (com 50\% de esterco) e $\mathrm{N}_{3}$ (com $75 \%$ de esterco); cinco lâminas de irrigação ajustadas quinzenalmente: $\mathrm{L}_{1}$ (com $25 \%$ da evapotranspiração), $\mathrm{L}_{2}$ (com $50 \%$ da evapotranspiração), $\mathrm{L}_{3}$ (com $75 \%$ da evapotranspiração), $\mathrm{L}_{4}$ (com $100 \%$ da evapotranspiração) e $\mathrm{L}_{5}$ (com 125\% da evapotranspiração), presença de cobertura morta (CC) e ausência de cobertura morta (SC).

O delineamento foi em blocos casualizados, com quatro repetições, perfazendo o total de 120 vasos (3 níveis de matéria orgânica x 5 lâminas de irrigação x 2 tratamentos com relação à cobertura morta $\times 4$ blocos) ficando as parcelas experimentais espaçadas $0,30 \times 0,30 \mathrm{~m}$ dentro do bloco e $0,60 \mathrm{~m}$ entre blocos. Cada parcela experimental (vaso) tinha uma área de $346,35 \mathrm{~cm}^{2}$.

Utilizaram-se 120 vasos funcionando à semelhança de lisímetros de drenagem, com capacidade de 5,95 L (diâmetro máximo de $21 \mathrm{~cm}$ e altura de $23 \mathrm{~cm}$ ); o sistema de drenagem foi composto de 0,3 L de brita, 0,3 L de areia e um recipiente plástico para coleta da água. Cada vaso recebeu aproximadamente o mesmo volume de solo devidamente destorroado e misturado com o esterco bovino curtido, conforme os tratamentos previstos de N1, N2 e N3, ficando, respectivamente, com os pesos de 6,2, 5,5 e 4,8 kg de solo mais esterco.

As sementes do cumaru (Amburana cearensis) utilizadas no experimento foram colhidas no município de Quixeramobim,CE, oriundas de plantas nativas cedidas por agricultores familiares ao Núcleo do IBAMA/MST para multiplicação em viveiros. A semeadura foi realizada no dia 11 de março de 2008, após seleção, eliminando-se as defeituosas e as que flutuaram após imersão em água. Um dia antes da semeadura as sementes foram pré-embebidas em água para facilitar o processo de germinação, ficando a $1 \mathrm{~cm}$ de profundidade em sementeira de terra vegetal, com pequena adição de esterco em camada superficial. A umidade foi mantida em capacidade de campo para facilitar a seleção de plantas mais vigorosas, por ocasião do transplante.

A finalização do experimento ocorreu aos 147 dias após a semeadura (DAS), tempo mínimo estimado para a produção de mudas de cumaru, em condições de serem transplantadas para o campo com o mínimo de mortalidade possível. O final deste período de 147 dias coincidiu com o período seco da região no qual não houve condições para transplante destas mudas no campo.

Considerando-se o fato do cumaru ser uma espécie nativa, sem tradição de cultivo, inclusive não havendo, na literatura, qualquer recomendação de adubação, optou-se por aplicar apenas o esterco previsto para cada tratamento. Os resultados das análises de solo e das misturas de solo mais esterco, realizadas no Laboratório de Solos da Universidade Federal do Ceará - FUNCEME, também não indicaram a necessidade de nenhuma correção.

Estabeleceram-se, por ocasião do preenchimento dos vasos (02/05/08), os tratamentos N1, N2 e N3, misturando-se o esterco curtido com o solo na proporção de 25, 50 e 75\% em volume, respectivamente.

Metade dos vasos (60) recebeu o tratamento de cobertura morta, logo no dia seguinte ao transplante das mudas. A cobertura morta foi oriunda da coleta de folhas e ramos finos já em processo de decomposição sobre o solo (serrapilheira), em uma área de caatinga com predominância de jurema preta (Mimosa sp.) e marmeleiro (Croton sp.).

Aplicou-se uma camada de aproximadamente $2 \mathrm{~cm}$ sobre o solo dos vasos que receberam a denominação de CC.

O início da aplicação das lâminas de irrigação ocorreu aos 86 DAS (30 dias após o transplante), com turno de rega de dois dias. Antes do inicio dos tratamentos, as irrigações foram realizadas aplicando-se uma lâmina de $400 \mathrm{ml}$ por vaso a cada dois dias. Este volume foi calculado considerando a evaporação media da área e a superfície evaporativa do vaso $\left(346 \mathrm{~cm}^{2}\right)$ considerando-se ser um volume capaz de manter o solo na capacidade de campo. Na diferenciação das lâminas, estas foram calculadas em função do balanço hídrico para os vasos sem restrição de umidade - Tratamento L4.

Na primeira irrigação, para calcular as lâminas, determinouse o volume de água consumido, subtraindo-se o volume drenado dos $400 \mathrm{ml}$ aplicados inicialmente para cada tratamento de esterco (N1, N2 e N3) e cobertura morta do solo (CC - com cobertura e SC - sem cobertura), obtendo-se, assim, seis médias (resultantes de 24 vasos) para os vasos que receberam lâminas de reposição total (100\% da ET - Tratamento L4): médias dos quatro blocos, dos vasos com os tratamentos L4N1SC, L4N2SC, L4N3SC, L4N1CC, L4N2CC e L4N3CC. Com estas médias é que foram calculados os volumes a serem aplicados nas irrigações subsequentes, conforme cada tratamento de água (L), esterco (N) e cobertura do solo (CC/SC), resultando em 30 tratamentos.

A cada quinze dias estas lâminas foram atualizadas, conforme o novo consumo mensurado (volume aplicado subtraído do volume drenado).

As variáveis estudadas foram a altura da planta, a taxa de crescimento absoluto da altura, o diâmetro caulinar e o número de folhas. A altura da planta $(\mathrm{em} \mathrm{cm}$ ) foi obtida medindo-se com uma régua milimetrada a distância desde o colo da planta até a sua extremidade mais alta. O diâmetro do caule foi determinado com um paquímetro digital, cujas leituras (em mm) foram realizadas na região do colo da planta. $\mathrm{O}$ número de folhas por planta, considerou-se apenas as folhas completamente abertas, com pelo menos $3 \mathrm{~cm}$ de comprimento (nervura principal), considerando-se que, somente acima destas medidas, elas são fotossinteticamente ativas. A taxa de crescimento absoluto da altura da planta, em $\mathrm{cm} \mathrm{dia}{ }^{-1}$, foi calculada de acordo com a Eq. 1: 


$$
\mathrm{TCAP}=\frac{\mathrm{A}_{2}-\mathrm{A}_{1}}{\mathrm{t}_{2}-\mathrm{t}_{1}}
$$

em que:

$$
\begin{aligned}
& A_{1} \text { - altura da planta no tempo } t_{1}, \mathrm{~cm} \\
& A_{2} \text { - altura da planta no tempo } t_{2}, \mathrm{~cm}
\end{aligned}
$$

\section{Analises estatística}

Os resultados foram analisados estatisticamente através do programa SISVAR, conforme metodologia de Ferreira (2007). Os contrastes entre as médias foram avaliados pelo teste " $F$ " (até $5 \%$ de probabilidade). Os graus de liberdade dos tratamentos com interações significativas foram decompostos em componentes de regressão polinomial quando se tratava de fator quantitativo (Ferreira, 2007). Entretanto, quando se tratava de fator qualitativo, realizou-se o desdobramento de um fator em função do outro e se aplicou o teste de Tukey (5\% de probabilidade).

\section{RESULTADOS E DISCUSSÃO}

\section{Altura de plantas (AP)}

É possível observar na Tabela 1 os resultados das análises de variância e as médias para a altura de plantas, com relação à quantidade de água aplicada (tratamentos L), esterco (N) e cobertura morta no solo (CC) e as interações do cumaru, aos 147 dias após a semeadura. Não se observa efeito significativo das diferentes lâminas de irrigação nem das doses de esterco sobre a altura da planta.

Angelim et al. (2007) trabalhando com cumaru em diferentes substratos, até a medição realizada aos 90 dias, constataram que todos os tratamentos apresentavam os mesmos resultados referentes ao aumento da altura das plantas.

Observa-se diferença significativa, no nível de $1 \%$ de probabilidade entre os tratamentos com cobertura morta e os sem cobertura (Figura 1). Aos 147 DAS, as plantas de cumaru no solo com cobertura tiveram uma maior altura $(20,5 \mathrm{~cm})$ que quando cultivadas no solo sem cobertura $(18,6 \mathrm{~cm})$. O maior crescimento em altura das plantas com cobertura em relação às sem cobertura, está provavelmente relacionado à maior eficiência no consumo de água e menor evapotranspiração da cultura. As plantas de cumaru no solo sem cobertura (SC) evapotranspiraram uma media de $4,32 \mathrm{~mm} \mathrm{dia}^{-1}$, Já as plantas no solo com cobertura (CC) usaram somente $2,53 \mathrm{~mm} \mathrm{dia}{ }^{-1}$ (Pimentel, 2008). Esta economia de água nas plantas que receberam cobertura morta em relação às que não receberam (41\%) é bastante razoável, porque a cobertura morta atua diminuindo muito a componente evaporação do solo. A presença de cobertura morta, com seus múltiplos efeitos no solo tais como a melhoria das suas condições químicas, físicas e biológicas (Borkert et al., 2003) e o controle das variações de temperatura no interior do solo, particularmente próximo da superfície, podendo favorecer consideravelmente o ambiente para o desenvolvimento da flora e da fauna do solo (Borkert et al., 2003; Resende et al., 2005). Isto é de grande importância nos solos do semiárido submetido a altas temperaturas ambientais.
Tabela 1. Resumo das análises de variância e médias para a altura de plantas (AP), em função da quantidade de água aplicada (L), esterco $(N)$ e cobertura morta no

\begin{tabular}{|c|c|c|}
\hline F.V. & G.L. & Quadrado médio \\
\hline 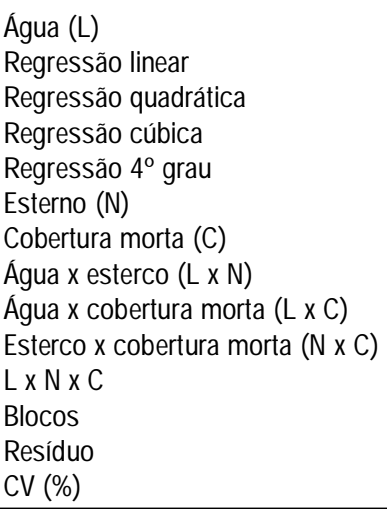 & $\begin{array}{l}4 \\
1 \\
1 \\
1 \\
1 \\
2 \\
1 \\
8 \\
4 \\
2 \\
8 \\
3 \\
87\end{array}$ & $\begin{array}{r}4,6146 \mathrm{~ns} \\
2,2168 \mathrm{~ns} \\
0,0150 \mathrm{~ns} \\
0,4440 \mathrm{~ns} \\
0,3001 \mathrm{~ns} \\
0,1313 \mathrm{~ns} \\
111,1688 * * \\
2,0430 \mathrm{~ns} \\
7,9396 \mathrm{~ns} \\
7,5063 \mathrm{~ns} \\
5,4177 \mathrm{~ns} \\
23,3243 \mathrm{~ns} \\
9,3128 \\
5,8016\end{array}$ \\
\hline $\begin{array}{l}\text { Lâminas de irrigação (L) } \\
\text { L1 }(0,25 \mathrm{ET}) \\
\text { L2 }(0,50 \mathrm{ET}) \\
\text { L3 }(0,75 \mathrm{ET}) \\
\text { L4 }(1,00 \mathrm{ET}) \\
\text { L5 }(1,25 \mathrm{ET})\end{array}$ & & $\begin{array}{c}\text { Média (cm) } \\
19,67 \\
19,67 \\
19,54 \\
18,73 \\
18,96\end{array}$ \\
\hline $\begin{array}{l}\text { Níveis de esterco }(\mathrm{N}) \\
\text { N1 }(0,25) \\
\text { N2 }(0,50) \\
\text { N3 }(0,75)\end{array}$ & & $\begin{array}{l}19,26 \\
19,30 \\
19,38\end{array}$ \\
\hline $\begin{array}{l}\text { Cobertura morta }(\mathrm{C}) \\
\text { CC (com cobertura) } \\
\text { SC (sem cobertura) }\end{array}$ & & $\begin{array}{l}20,28 \mathrm{a} \\
18,35 \mathrm{~b}\end{array}$ \\
\hline Média (cm) & & 19,31 \\
\hline
\end{tabular}
solo (CC) e suas interações, aos 147 dias após a semeadura - DAS

** Significativo no nível de $1 \%$ de probabilidade $(p<0,01)$; ns - não significativo $(p$ e" 0,05$)$ pelo teste de $F$. As médias seguidas da mesma letra na coluna não diferem estatisticamente entre si pelo Teste de Tukey ao nível de $5 \%$ de probabilidade

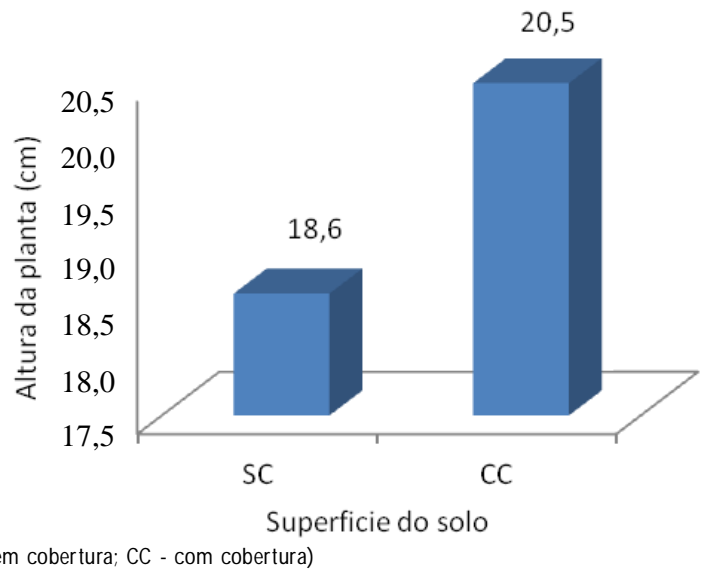

Figura 1. Efeito da cobertura do solo na altura das plantas do cumaru

\section{Taxa de crescimento absoluto da altura de plantas}

Encontram-se, na Tabela 2, os resultados do comportamento da Taxa de Crescimento Absoluto da Altura de Plantas com relação à influência das lâminas de irrigação, esterco aplicado no transplante, por ocasião do enchimento dos vasos e presença de cobertura morta no solo; a partir dos 87 dias após a semeadura (DAS), quando começou a variação das 
quantidades de água aplicada em cada tratamento até os 147 DAS, perfazendo o total de sessenta dias. Observa-se que não houve aumento nas taxas de crescimento absoluto da altura de plantas (TCAAP) com o aumento das lâminas de irrigação nem com o aumento do esterco ou, ainda, com a presença de cobertura morta no solo.

Tabela 2. Resumo das análises de variância e médias para a taxa de crescimento absoluto de altura de planta (TCA AP), em função da quantidade de água aplicada $(\mathrm{L})$, esterco (N) e cobertura morta no solo (CC) e suas interações, do cumaru dos 87 aos 147 dias após a semeadura - DAS

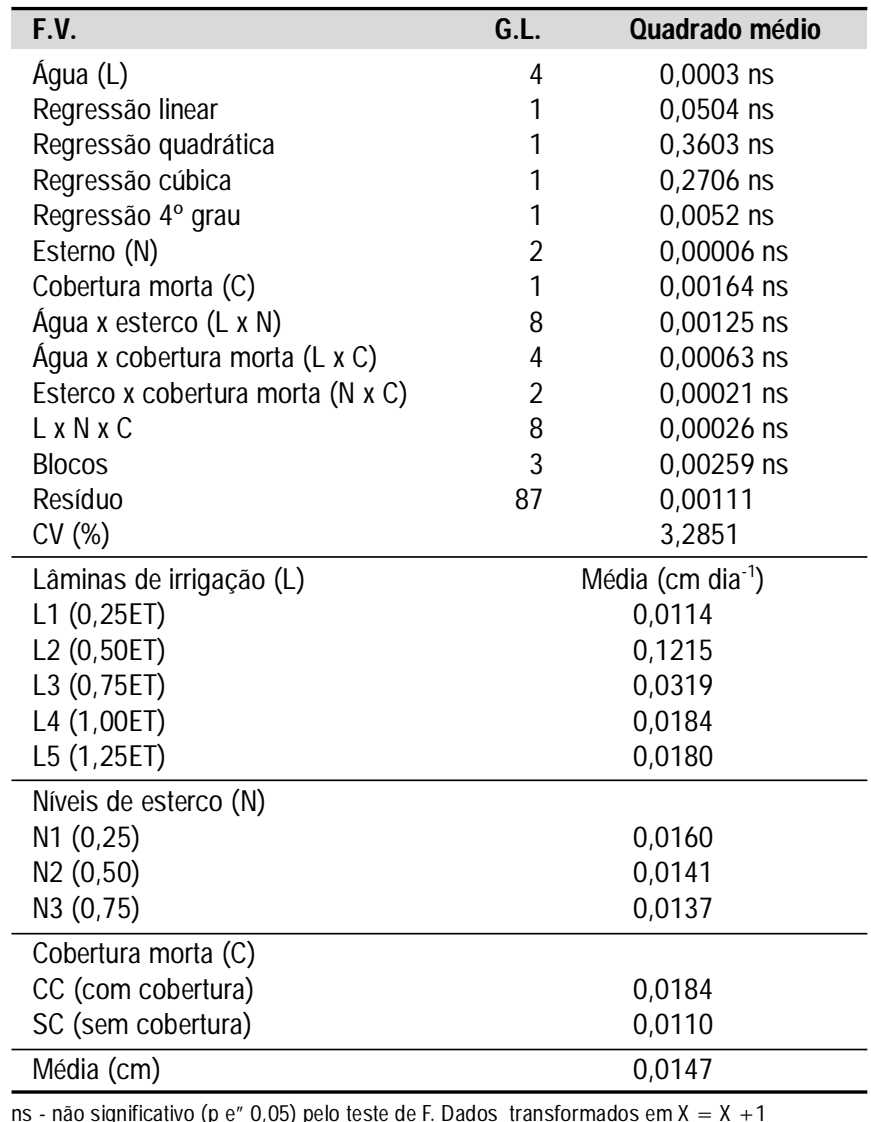

As mudas que apresentaram as menores taxas de crescimento absoluto da altura de plantas (TCA AP) podem estar translocando nutrientes para as partes subterrâneas, à semelhança do que foi observado por Ramos et al. (2004), com mudas de cumaru em pleno sol, em que cerca de $80 \%$ da biomassa total da planta era do sistema radicular. O cumaru, por ser uma planta nativa e apresentar o fenômeno da deciduidade, perdendo as folhas, independentemente do conteúdo de água do solo, apresenta um padrão de crescimento de parte aérea totalmente diferente das culturas tradicionais, com sucessivas fases de declínio e aumento da sua altura (Trovão et al., 2007; Pimentel, 2008).

Assim, os resultados obtidos no presente trabalho diferem daqueles encontrados na maior parte dos trabalhos, que constatam que a aplicação de água e matéria orgânica incrementa o crescimento e desenvolvimento das plantas. No entanto, a espécie $A$. cearensis parece estar bem adaptada às condições adversas como falta de água e também à reduzida concentração de matéria orgânica, de macro e de micronutrientes no solo. Esta adaptação, provavelmente, deve ter contribuído no presente para que as plantas apresentassem o melhor crescimento e desenvolvimento morfológico em solo sem aplicação de matéria orgânica, fato constatado também por Angelim et al. (2007).

\section{Diâmetro caulinar}

Verifica se na Tabela 3 a resposta do diâmetro caulinar do cumaru ao fim do experimento em função das diferentes quantidades de água aplicadas, esterco e cobertura morta no solo. Da mesma forma que para a altura da planta, não houve influência das lâminas de irrigação nem do esterco aplicado sobre o diâmetro caulinar das mudas de cumaru, nem da natureza da cobertura do solo.

Tabela 3. Resumo das análises de variância e médias para o diâmetro caulinar (DC), em função da quantidade de água aplicada (tratamentos L), esterco(N) e cobertura morta no solo (CC) e suas interações, do cumaru aos 147 dias após a semeadura - DAS

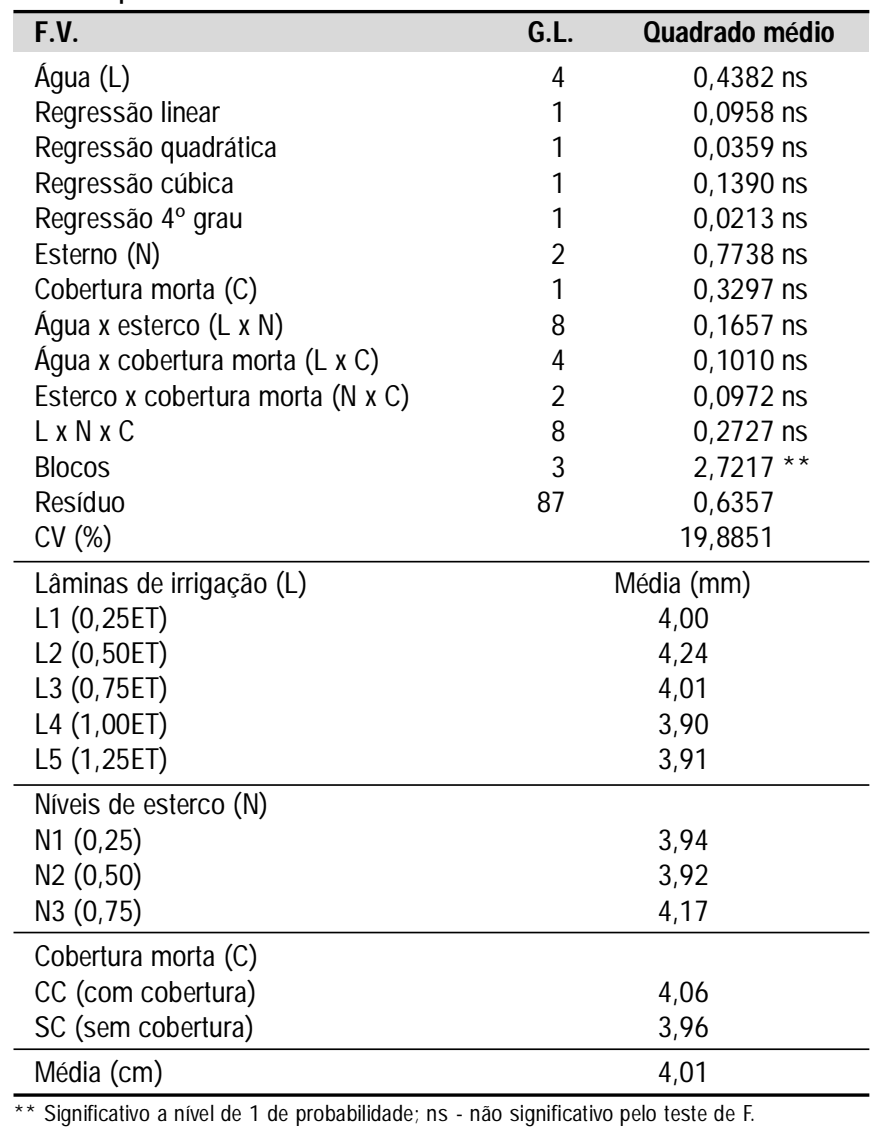

Semelhantemente, Angelim et al. (2007) também não encontraram diferenças significativas de diâmetros caulinares de cumaru, em diferentes substratos, até 90 dias.

$\mathrm{Na}$ Tabela 3 pode-se observar que, embora não estatisticamente significante, os maiores diâmetros caulinares nas plantas foram obtidos com as menores lâminas, de irrigação e com os maiores níveis de esterco no solo, sendo, portanto, uma relação inversa entre diâmetro caulinar e o número de 
folhas, visto que, nesta combinação de menores lâminas com maiores quantidades de esterco no solo, se encontrou menor número de folhas, havendo, para a menor lâmina menor resposta em número de folhas, com relação às quantidades de esterco presentes no solo e uma resposta maior em diâmetros caulinares, para os mesmos tratamentos. Isto poderia ser explicado pela relação fonte e dreno (Taiz \& Zeiger, 2004) de fotoassimilados, uma vez que é provável que as mudas de cumaru estejam acumulando reservas no caule (com aumento de diâmetro) em detrimento do crescimento da planta em número de folhas, sobretudo pelo processo de perda das folhas, que antes de cair funcionavam como fonte. Seria, portanto, um dos mecanismos de adaptação das espécies nativas ao ambiente da caatinga, como os tradicionais citados por Trovão et al. (2007), e merece ser melhor estudado.

\section{Número de folhas (NF)}

$\mathrm{Na}$ Tabela 4 observa-se que no período analisado (147 dias após a semeadura) o número de folhas por plantas não foi influenciado pela irrigação, pelas quantidades de esterco adicionadas no transplante nem pela presença da cobertura morta no solo, o que poderia ser explicado pelo comportamento caducifólio da espécie, independente da disponibilidade de água ou de nutrientes para a planta. Apesar

Tabela 4. Resumo da análises de variância e médias para o número de folhas (NF), em função da quantidade de água aplicada (L), esterco (N) e cobertura morta no solo (CC) e suas interações do cumaru aos 147 dias após a semeadura - DAS

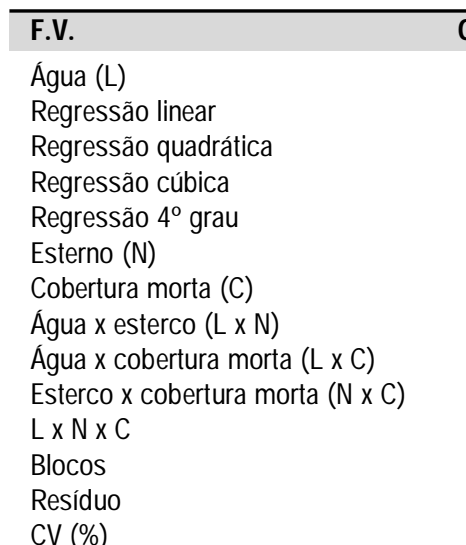

\begin{tabular}{cc} 
G.L. & Quadrado médio \\
4 & $0,00569 \mathrm{~ns}$ \\
1 & $2,84445 \mathrm{~ns}$ \\
1 & $0,19841 \mathrm{~ns}$ \\
1 & $0,04444 \mathrm{~ns}$ \\
1 & $0,00992 \mathrm{~ns}$ \\
2 & $0,00613 \mathrm{~ns}$ \\
1 & $0,00173 \mathrm{~ns}$ \\
8 & $0,00564 \mathrm{~ns}$ \\
4 & $0,01213 \mathrm{~ns}$ \\
2 & $0,00984 \mathrm{~ns}$ \\
8 & $0,00467 \mathrm{~ns}$ \\
3 & $0,02699 * *$ \\
87 & 0,00591 \\
& 0,5378 \\
\hline
\end{tabular}

\begin{tabular}{lc} 
Lâminas de irrigação $(\mathrm{L})$ & Média sem transformação (folhas) \\
L1 $(0,25 \mathrm{ET})$ & 3,67 \\
L2 $(0,50 \mathrm{ET})$ & 4,04 \\
L3 $(0,75 \mathrm{ET})$ & 4,38 \\
L4 $(1,00 \mathrm{ET})$ & 4,71 \\
L5 $(1,25 \mathrm{ET})$ & 4,67 \\
\hline Níveis de esterco (N) & \\
N1 $(0,25)$ & 4,70 \\
N2 $(0,50)$ & 4,10 \\
N3 $(0,75)$ & 4,08 \\
\hline Cobertura morta (C) & \\
CC (com cobertura) & 4,40 \\
SC (sem cobertura) & 4,18 \\
\hline Média (cm) & 4,29
\end{tabular}

** Significativo a nível de $1 \%$ de probabilidade $(p<0,01)$; ns - não significativo. Dados transformados por $x=\sqrt{x+200}$. As médias seguidas da mesma letra não diferem estatisticamente entre si pelo Teste de Tukey a nível de $5 \%$ de probabilidade de não existir, na literatura, referências com relação ao efeito da irrigação em mudas de cumaru, Ramos et al. (2004) estudando mudas desta cultura, dos quatro aos 19 meses de idade, observaram diferenças no ritmo de queda de folhas associado à estacionalidade climática, com diferenças muito grandes entre a estação chuvosa e a estação seca, mesmo sob irrigação.

A falta de resposta da planta em relação à água aplicada é justificada pelo fato do cumaru pertencer, conforme Pimentel (2008), a um grupo de plantas da caatinga que perde folhas mais cedo e inicia a brotação durante a estação seca, e que a maioria dessas plantas apresentam correlação com o fotoperíodo e não com a ocorrência de chuvas na emissão ou perda de folhas, afetando assim o seu crescimento. Borchert \& Rivera (2001) em estudo com espécies arbóreas de caules suculentos verificaram que essas plantas permaneciam inativas do início para o meio da estação seca, até mesmo quando eram irrigadas. Concluíram que a disponibilidade de água não estava determinando a ocorrência do brotamento, e que a variação sazonal no fotoperíodo era o fator que determinava a ocorrência das fenofases vegetativas e não a disponibilidade de água no solo, mesmo em baixas latitudes, onde a variação anual do comprimento do dia é inferior a uma hora, sendo a dormência induzida e quebrada por variações no fotoperíodo de menos de 30 min.

Figueiredo (2008) também afirma que períodos de crescimento e dormência alternam-se mais sincronizados com as variações no fotoperíodo, energia radiante e temperatura do que com a sazonalidade na precipitação.

O fato do cumaru na sua fase de muda não ter sido afetado pelo conteúdo de água do solo não significa que em fases fenológicas posteriores não possa manifestar algum efeito, assim não é possível indicar que não precisa ser irrigada. Se a escassez de água for muito alta na região, talvez poderia recomendar se irrigar com a menor lâmina $(0,25 \%$ ET).

Angelim et al. (2007) trabalhando com cumaru no semiárido, verificaram que o efeito de tratamentos com diferentes quantidades de esterco na formação de folhas começaram a se manifestar a partir dos 90 dias após o transplante e ainda assim o número de folhas foi melhor nas plantas que não receberam esterco.

\section{CONCLUSÕES}

1. Com exceção da altura das plantas, afetada pela natureza da cobertura do solo, nenhuma das variáveis estudadas (altura, taxa de crescimento absoluto, diâmetro caulinar e número de folhas) foi afetada significativamente pelos tratamentos de água do solo, matéria orgânica e cobertura do solo.

2. A presença de cobertura morta no solo aumentou significativamente a altura das mudas.

3. O uso de cobertura morta significou uma economia de $41 \%$ da água de irrigação utilizada. 


\section{LITERATURA CITADA}

Angelim, A. E. S.; Moraes, J. P. S.; Silva, J. A. B.; Gervásio, R. C. R. G. Germinação e aspectos morfológicos de plantas de Umburana de Cheiro (Amburana cearensis) encontradas na região do Vale do São Francisco. Revista Brasileira de Biociências, v.5, p.1062-1064, 2007.

Borchert, R.; Rivera, G. Photoperiodic control of seasonal development and dormancy in tropical stem succulent trees. Tree Physiology, v.21, p.213-221, 2001.

Borkert, C. M.; Gaudêncio, C. A.; Pereira, J. E.; Pereira, L. R.; Oliveira Júnior, A. Nutrientes minerais na biomassa da parte aérea em culturas de cobertura do solo. Pesquisa Agropecuária Brasileira, v.38, p.143-153, 2003.

Canuto, K. M.; Silveira, E. R.; Bezerra, A. M. E. Estudo fitoquímico de espécimens cultivados de cumaru (Amburana cearensis A. C. Smith) . Química Nova, v.33, p.662-666, 2010.

Carvalho, D. F.; Montbeller, C. A.; Cruz, E. S.; Lana, A. M. Q.; Silva, W. A. Efeito da cobertura morta e do preparo do terreno nas perdas de solo e água em um Argissolo vermelho-amarelo. Engenharia na Agricultura, v.11, p.15-22, 2003.

Duarte, R. F.; Sampaio, R. A.; Brandão Júnior, D. S.; Fernandes, L. A.; Silva, H. P. Crescimento inicial de acácia em condicionador formado de fibra de coco e resíduo agregante. Revista Brasileira de Engenharia Agrícola e Ambiental, v.14, p.1176-1185, 2010.

Ferreira, D. F. Sisvar Versão 5.0. Lavras: UFLA, 2007.

Figueiredo, P. S. Fenologia e estratégias reprodutivas das espécies arbóreas em uma área marginal de cerrado, na transição para o semi-árido no nordeste do Maranhão, Brasil. Revista Trópica - Ciências Agrárias e Biológicas, v.2, p.822, 2008.

Gasparim, E.; Ricieri, R. P.; Silva, S. L.; Dallacort, R.; Gnoatto, E. Temperatura no perfil do solo utilizando duas densidades de cobertura e solo nu. Acta Scientiarum Agronomy, v. 27, p.107-115, 2005.
Guedes, R. S.; Alves, E. U.; Gonçalves, E. P.; Braga Júnior, J. M.; Viana, J. S.; Colares, P. N. Q. Substratos e temperaturas para testes de germinação e vigor de sementes de Amburana cearensis (Allemão) A. C. Smith. Revista Árvore, v.34, p.5764, 2010.

Marinho, I. V.; Freitas, M. F.; Zanella, F. C. V.; Caldas, A. L. Espécies vegetais da caatinga utilizadas pelas abelhas indígenas sem ferrão como fonte de recursos e local de nidificação. In: Congresso Brasileiro de Extensão Universitária, 1, 2002. João Pessoa. Anais... João Pessoa: Editora Universitária, 2002. CD Rom.

Pimentel, J. V. F. Níveis de água, matéria orgânica e cobertura morta na produção de mudas de cumaru - Amburana cearensis. Campina Grande: UFCG, 2008. 64p. Dissertação Mestrado

Ramos, K. M. O.; Felfili, J. M.; Fagg, C. W.; Silva, J. C. S.; Franco, A. C. Desenvolvimento inicial e repartição de biomassa de Amburana cearensis (Allemao) A. C. Smith, em diferentes condições de sombreamento. Acta Botânica Brasilica, v.18, p.351-358, 2004.

Resende, A. S.; Azevedo, C. R.; Lima, K. D. R.; Carpeggiane, B. P.; Araújo, J. E.; Miranda, C. A. K. Produção e qualidade de mudas de espécies florestais. In: Resende, A. S.; Chaer, G. M. Manual para recuperação de áreas degradadas por extração de piçarra na Caatinga. Seropédica: Embrapa Agrobiologia, 2010, cap.2, p.13-28.

Resende, F. V.; Souza, L. S.; Oliveira, P. S. R.; Gualberto, R. Uso de cobertura morta vegetal no controle da umidade e temperatura do solo, na incidência de plantas invasoras e na produção de cenoura em cultivo de verão. Ciência e Agrotecnologia, v.29, p.100-105, 2005.

Taiz, L.; Zeiger, E. Fisiologia vegetal. 3.ed. Porto Alegre: Artmed, 2004. 722p.

Trovão, D. M. B. M.; Fernandes, P. D.; Andrade, L. A. de; Dantas Neto, J. Variações sazonais de aspectos fisiológicos de espécies da Caatinga. Revista Brasileira de Engenharia Agrícola e Ambiental, v.11, p.307-311, 2007. 